\title{
On the Artistry and Negative Effects of Sadomasochism
}

\author{
Ning Wang \\ Minsheng College \\ Henan University \\ Kaifeng, China
}

\begin{abstract}
Sadomasochism is a spiritual demand and expression attached to sex and emotion. It is a performance art, under the condition of mutual free will and based on some fixed pattern or conventional rule, which is to conduct controlling and being controlled, compelling and being compelled with focus on the bearing limit and will of Sadomasochism object (masochist), so as to achieve mutual balance in libido, sexual desire, possessiveness, belongingness, sense of loss and sense of guilt, etc.
\end{abstract}

\section{Keywords—sadomasochism; perform art; negative effects}

\section{INT RODUCTION}

$\mathrm{Sm}$, abbreviation for Sadomasochism, is a compound word of Sadis m and Masochism. Professor Pan, Guangdan translated SM into "Sadomasochism" which contains the eastern cultural context and meaning, whilst indicating that this propensity is related to people's emotions, instead of merely sadism and masochism. So what is Sadomasochism in the world? How should it get defined? And how does it develop in traditional Chinese culture and idea?

\section{BRIEF INT RODUCTION OF CURRENT SADOMASOCHISM SITUATION IN CHINA}

Sadomasochism is a psychological activity and behavior existing in all ages, including in different countries, races, civilizations and fields, also with blinding traces left from historical materials, literature, film and television and news, etc. There are such abundant literary works following the clue and topic of Sadomasochism as "Beauty's Feet" by famous Chinese writer Yi Nong in 2009, and "Fifty Shades of Grey" by American writer E. L.James in 2011, one of the best-sellers and filmed in 2015. Sadomasochism in common literary and artistic works is even more too numerous to mention. However, this new object is not so well-known, mainly attributed to the traditional Confucianism and Buddhism cultures showing continence and abstinence ideas to some extent while intentionally avoiding the abnormality and negative effects of Sadomasochism, which is right as described in "subculture" of "Sadomasochism Subculture" by famous sociologist Li Yinhe. In brief, Sadomasochism, corresponding to mainstream culture, is a non-mainstream, minority, local and marginalized behavior which is classified into secondary scope of thematic culture. At this stage, only a few unblocked Sadomasochism websites, and "under the dark rule" Sadomasochism clubs in developed cities are deemed as communication platforms for Sadomasochism. Though Sadomasochism is effectively controlled by the society from spreading, people who suffer from it need to be confronted or given scientific counseling.

Sadomasochism is caused by Sadomasochism consciousness which exist as a subconsciousness not mentioned nor confronted but constantly playing a role in people's life as a undeveloped and unused potency hidden in deeper consciousness and governing personal thinking and behaving. Subconsciousness is a mysterious power hidden under our common consciousness, a thought relative to "cons ciousness". In that way, why human beings would have such consciousness Sadomasochism?

\section{GENERATION OF SADOMASOCHISM AND RECTIFICATION OF IT S DEFINITION}

Sadomasochism consciousness is formed not of single factor as sex game, role play, fetish complex, Electra (Oedipus: need of being punished) complex, sense of quilt (Freud) psychopathic personality, etc will all lead adults or even juvenile to falling into Sadomasochism mentality. In reality, Sadomasochism participants do not appear to be a cluster or group, regardless of age, gender, industry, stratification, and field. They vary from individualists with distinct personality and forward-thinking to fetish complex people suffering from complicated thinking, sensitivity, selfclosing or lack of security, and to group with Sadomasochism consciousness and behavior resulted from mental over-loading due to long-term excessive pressure. As to a deeper analysis of Sadomasochism causes, there is yet to be clear and simple definition in academic circles. Sadomasochism is rooted in the animality and natural quality in human nature, which mainly includes two patterns as normal sexual arousal and sexual arousal from Sadomasochism and which is a similarity between human and animal. Sadomasochism cannot be separated from human's sexual need and emotional nature, consciousness and behavior attached beneath the surface of sex and emotion. Different factors and value orientations developing Sadomasochism consciousness have contrast and duality, unable to have cause-and-effect phenomenon analysis given. Freud: explanation that Sadomasochism is caused by sense 
of guilt is stuffless as many cases have proved that Sadomasochism also comes into being without that sense. Li Yinhe defined Sadomasochism as: "it is a sexuality connecting pleasure and pain, or gaining pleasure from pain. It must be explained that the pain hereinabove has two connotations, namely physical pain (e.g. from whipping) and emotional pain (from humiliation in domination and subordination relationship) Exerting pain on others and bringing into autologous heat belongs to sadism category while receiving pain and bringing into it, masochism category. Main contents in Sadomasochism relationship are domination and subordination and behavior leading to psychological and physical pain."1 This is most influential definition for Sadomasochism ever, fit for western culture characteristics, with the excessive and single emphasis on pleasure and pain in Sadomasochism, and neglect of comprehensive factors of this behavior.

Sadomasochism reaches role interaction and effective coordination and sexual arousal successively through sadist or masochist's emotional communication and bodily experience. Some non-visual aesthetic connotations are conveyed by role communication and integration, and a special performance art is formed in a specific time and place. Therefore, Sadomasochism is a performance art, not only conforming to the art in definition and concept aspects, but an avant-garde and conceptual art in visual art category. It, employing control, restriction, role-play, consciousness pervasion, etc, emphasizes the thoughts and ideas behind sadist or masochist, with its artistry existed in the mind of sadist or masochist themselves and "audience" who can understand this behavior. Thereby, the definition of Sadomasochism is rectified. Sadomasochism is a spiritual demand and expression attached to sex and emotion. It is a performance art, under the condition of mutual free will and based on some fixed pattern or conventional rule, which is to conduct controlling and being controlled, compelling and being compelled with focus on the bearing limit and will of Sadomasochism object (masochist), so as to achieve mutual balance in libido, sexual desire, possessiveness, belongingness, sense of loss and sense of guilt, etc.

\section{ANALYSIS ON ARTISTRY AND NEGATIVE EFFECT S OF SADOMASOCHISM}

Combining Sadomasochism with such broad noun as "artistry" does not mean that Sadomasochism holds the traditional, standard and strict aesthetic concept, but the artistic elements. Primarily, main characteristic of Sadomasochism is to express the exaggeration and unconventionality of sex and emotion; all sourced from real relationships and stories in life, compellation, possession and subordination embody the formalization and reformation by role, identity, scene and prop in Sadomasochism. Role and character features in Sadomasochism also contain fortitude, loyalty, charm and femininity, etc of hu man nature. Secondly, performing art play an extreme important role in Sadomasochism; role's dressing, binding method, macram, dialog, and scene arrangement all would bring to some extent visual aesthetic quality and metal sentiment to Sadomasochism while outer image of Sadomasochism and language application are rather significant to convey emotions. Furthermore, people who can engage in professional Sadomasochism should be equipped with complete knowledge structure, integrated personality, high cultural accomplishment, aesthetic sentiment and professional quality, able to thoroughly understand and master diversified value orientations with their practical skills and good psychological quality. Sadomasochism behavior is kind of experience and game in human emotional activities, which may contribute to the meditation and promotion of human nature perfection if idealized, while it would be a manifestation of human nature degeneration, social and civilization regression if lifelized by opposing its ratification and performization.

The above-mentioned is only an idealized demonstration for Sadomasochism as an artistic behavior which in fact is indeed in a sub-health status. Though with developing space under network and media restrictions, Sadomasochism still remains in a stage where little people dare to care or defend it. Sadomasochism group is in a chaos, under no strict regulations and legal judgment basis, nor conventional determination habit; Sadomasochism participants are unstable and uneven, leaving the conventionality and health of Sadomasochism behavior unguaranteed. In other words, rationality and legality of Sadomasochism behavior have not come into systematic and common social recognition, which derecognition would make it unavoidable for physical hurt and aggregate the abnormality of sadomasochists. Obscene, closing, self-abasement and fleshliness all are common phenomena for people who are passionate with or cling to Sadomasochism behavior. More seriously, this special behavior and the role sensitivity in our traditional ethics will bring a heavy burden of ethical pressure and social opinion to sadomasochists, which in a certain period and scope will generate a vicious circle to both body and mind. Encouragement and recognition given by $\mathrm{Li}$ Yinhe to Sadomasochism health unilateral, and the positive significance of Sadomasochism she thinks is too far being a overwhelming advantage against to the negative influences on most people. By "delicate" and "elegant" she uses to describe Sadomasochism, saying that when communicating with sadomasochists: "they have their own group and website, happy and rather healthy", which phenomena is transient and belong only to a handful of individualists and people who deviate from social mainstream cultures and who can master such performance art and role play as Sadomasochism. Li Yinhe perfects Sadomasochism, not aware of the naked and filthy lust expressions in most sadomasochist activities, nor objectively looking at the reality that a great number of people trapped in Sadomasochism are subject to mental self-accusation and psychic pain, unable to get scientific counseling. Thus, she ignores the negative and effects from Sadomasochism behavior on Sadomasochism individual, the traditional culture maintaining healthy social development, and social orientation taking positive energy as main values.

Under the background of age of diversified values and aesthetics, we should recognize the disadvantages of Sadomasochism behavior. Proportion of people who can 
understand, recognize and accept Sadomasochism behavior is remarkably unusual while Sadomasochism behavior is against the wall in practical operation and role implementation process, playing a negative and dim guiding role in promoting adolescent sanity and healthy thinking. It is impossible for Sado masochis m to scientifically and healthily exist in the ideal will of Sadomasochism group or sociologists who support it, so what is recognized by $\mathrm{Li}$ Yinhe is only a case. Sadomasochism is the hotbed to cultivate psychopathic personality, killer to destroy healthy growth of adolescents as it can easily foster new Sadomasochism participants once implanted into the thinking of people who have Sadomasochism subconsciousness. Literary works, film and television programs can easily get spread in network and media era nowadays, Sadomasochism and foot fetish becoming public a literary type with relevant user-generated videos, film and television works emerged endlessly. Though monitored and forced out to some extent, many unhealthy and information register abroad, bringing about resistance to regulation work. Network platform should strengthen anti-Sadomasochism education by encouraging to establish such forums and to reveal disadvantages and negative effects behind Sadomasochism behavior with an end to lead people to healthy life and establish anti-Sadomasochism concept.

\section{SADOMASOCHISM BEHAVIOR DEVELOPMENT PREDICATION}

As the main part of the Chinese nation, Han nationality is not likely to treat Sadomasochism as an allowable folk custom in the orthodox and mainstream cultural idea where Sadomasochism behavior is firmly rejected, that is to say, there is no soil for Sado masochism growth and development. Nevertheless with the fast development of Chinese economy, people's substance level will get further improved, so will the ideological emancipation and overall require ments on life quality, under which circu ms tance, people will exploit a new world concerning the exploration, practice and artistic manifestation under their own cultural system, especially when the Chinese and foreign cultures recover and develop in the deep communication and integration over personality, they will get full and scientific view of Sadomasochism from the aspect of consciousness and theory providing that Sadomasochism itself is unacceptable in China. Even if it can become a free and happy artistic behavior without hurting others, even if it presents a colorful and irresistible aesthetic world, recognition and opposition from people under the traditional idea and consciousness will also rise. In this sense, Chinese people will gain an unprecedented understanding and perception of Sadomasochism's negative effects.

Many people are obsessed with Sadomasochism unable to extricate themselves, to which prevent and counseling is imperative but social public service system especially network platforms lack of positive guidance and scientific demonstrations as the society avoid the existence of Sadomasochism behavior and the education to Sadomasochism group as well. Sadomasochism behavior has turned into a hidden social need, and long ago an underground transaction market meeting the needs of Sadomasochism group who have been deeply aware the negative effects while having trouble in finding a positive counseling method for they are unable to share it with any acquaintances, and so-called psychologists and common physiologists are too far from being capable of treating it. Though indirectly connected to sexual behavior, Sadomasochism itself is a branch of it only being heterized and processed to appear "elegant" and "delicate". If not separately listed out, anti-Sadomasochism should belong to category of abstained from sexual relations and whoredoms. In most cases, Sadomasochism could only do more harm to people's physical and psychological health, adolescents in particular. In the future, the society should attach importance to Sadomasochism group by proceeding with establishing systematic and positive anti-Sadomasochism network platforms, employing knowledge and science to fully guide them to give up inappropriate Sadomasochis m behavior and mental disorders and welco me a healthy, sunny and positiveenergy life form.

\section{REFERENCES}

[1] Li Yinhe. "Sadomasochism Sub-culture"[M]. Beijing: China Today Publishing House. 1998

[2] Wang Fuxiang. Sadomasochism Mentality of Chinese People and Sadomasochism Description in Literary[J]. Xiangtan Normal University Academic Journal (Social Science Edition), 2008-01-10.

[3] Gu Baoyi. Extreme Love Experience in Subjective Culture-on Research of Mentality in "Fifty Shades of Grey". Chinese Postgraduates, 2015-08-16. 